\title{
Effects of Height of F2-Layer on Critical Frequency by Use of Data at Ouagadougou Station
}

\author{
Emmanuel Nanéma ${ }^{1,2}$, Moustapha Konaté ${ }^{2}$, Doua Allain Gnabahou ${ }^{2} \&$ Frédéric Ouattara $^{2}$ \\ ${ }^{1}$ Centre National de la Recherche Scientifique et Technologique (CNRST), Institut de Recherche en Sciences \\ Appliquées et Technologies (IRSAT), 03 BP 7047 Ouagadougou 03, Burkina Faso \\ ${ }^{2}$ Université Norbert ZONGO, Laboratoire de Recherche en Météorologie de l'Espace (LAREME), Koudougou, \\ Burkina Faso \\ Correspondence: Emmanuel Nanéma, Centre National de la Recherche Scientifique et Technologique (CNRST), \\ Institut de Recherche en Sciences Appliquées et Technologies (IRSAT), 03 BP 7047 Ouagadougou 03, Burkina \\ Faso. E-mail: nanema_emmanuel@yahoo.fr
}

Received: August 13, 2018

Accepted: August 29, 2018

Online Published: September 27, 2018

doi:10.5539/apr.v10n5p57

URL: https://doi.org/10.5539/apr.v10n5p57

\begin{abstract}
Ionosphere investigation leads to the knowledge of its composition in particles. The particle density and composition determine the capacity of this region to reflect radio waves in the atmosphere at different heights. Some variables such as season, solar cycle phase also influence the ionosphere behavior. Radio waves frequencies pass through the ionosphere layer without reflection above a critical value determining the critical frequency. This study determines the critical frequency of radio waves in the F2 layer (foF2) of the ionosphere by use of data at Ouagadougou station during the minimum and the maximum of solar cycle 22, at different seasons with the height of F2-layer (hmF2). Daytime and nighttime also influence ionosphere parameters. The study presents the hourly behavior of foF2 according to $\mathrm{hmF} 2$ values.
\end{abstract}

Keywords: Ionosphere, critical frequency, height of F2-layer, solar cycle phases

\section{Introduction}

This work deals with the critical frequency variability in the F2-layer. In previous studies (Ouattara \& Nanéma, 2014), (Ouattara, 2013) we determined the foF 2 variability at Ouagadougou (lat $=12.4^{\circ} \mathrm{N}$, long $=358.5^{\circ} \mathrm{E}$, West Africa) station. By use of foF2 and foE data provided by Telecom Bretagne and with the help hmF2 values (Ouattara \& Nanéma, 2013), we determine the hourly profiles of critical frequency of F2-layer under quiet time variation at Ouagadougou station during the minimum and the maximum of solar cycle 22 and the effects of $\mathrm{hmF} 2$ hourly variability on this parameter. The study also considers the seasonal effects on foF 2 and hmF2 hourly variability during equinox and solstice months. Some hourly data of foF2 are missing in Telecom Bretagne database.

\section{Materials and Methods}

The methodology of the study is based on the five quietest days of each month in the minimum and the maximum of solar cycle phases. Solar cycle phases are determined by the yearly average of Zürich Sunspot number Rz. The minimum phase is obtained for $\mathrm{Rz}<20$ while the ascending phase and maximum phase are respectively obtained with $20 \leq \mathrm{Rz} \leq 100$ and $\mathrm{Rz}>100$ (Zerbo et al, 2011; Ouattara et al 2012; Gnabahou \& Ouattara, 2012). Quiet days are determined by considering Aa $\leq 20 \mathrm{nT}$.

With these criteria, the retain days are indicated in the Table 1.

Table 1. Retain days for the study

\begin{tabular}{ccccccc}
\hline \multicolumn{1}{c}{$\begin{array}{c}\text { Solar } \\
\text { cycle }\end{array}$} & Phase & Year & $\begin{array}{c}\text { March } \\
\text { (Equinox) }\end{array}$ & $\begin{array}{c}\text { June } \\
\text { (Solstice) }\end{array}$ & $\begin{array}{c}\text { September } \\
\text { (Equinox) }\end{array}$ & $\begin{array}{c}\text { December } \\
\text { (Solstice) }\end{array}$ \\
\hline \multirow{2}{*}{22} & Min & 1985 & $9,13,21,22,25$ & $3,14,16,18,19$ & $2,3,4,5,29$ & $8,9,21,23,29$ \\
& Max & 1990 & $4,10,16,17,31$ & $16,17,20,21,30$ & $2,3,27,29,30$ & $10,11,19,21,29$ \\
\hline
\end{tabular}


The study uses the data values of foE and foF2 provided by Telecom Bretagne database. The height of F2-layer (Dudeney, 1983; Zhang et al, 2003) is given by (1)

$$
\mathrm{hmF} 2=\frac{1490 \mathrm{MF}}{\mathrm{M}+\Delta \mathrm{M}}-176
$$

where

$$
M F=M \sqrt{\frac{0.0196 M^{2}+1}{1.2967 M^{2}-1}}
$$

And

$$
\Delta \mathrm{M}=\frac{0.253}{\frac{\text { foF } 2}{\text { foE }}-1.215}-0.012
$$

$\mathrm{M}$ indicates the factor of propagation $\mathrm{M}(3000) \mathrm{F} 2$, and foE the critical frequency in the E-Region. The knowledge of foE and foF2 helps to determine the hourly values of $\Delta \mathrm{M}$.

Note that for missing hourly data of foE and foF2, the profiles are not completed.

\section{Results and Discussion}

hmF2 and foF2 time variation given by data for solar minimum (year 1985) are shown on Figure 1 (Panels (a), (b), (c), (d)). On Figure 2 (panels (a'), (b'), (c'), (d')), we present hmF2 and foF2 time variation given by data for solar maximum (year 1990) of C22.

The linear trend lines show that foF2 grows rapidly while hmF2 is quiet constant (Figure 1: panels (a), (b), (c) and (d)) on solar minimum. This is shown by a steep slope of the linear trend line for foF2 while hmF2 presents a flat slope. On solar maximum, hmf2 and foF2 linear trend lines present a steep slope (Figure 2: panels (a'), (b'), (c') and (d')). hmF2 and foF2 present higher values at solar maximum than those at solar minimum. So, during solar maximum, the critical frequency gets high value, compared to minimum solar cycle phase. While $\mathrm{hmf} 2$ grows from solar minimum to solar maximum, foF2 also grows. This means that from solar minimum to maximum, the critical frequency gets high values. This can be explained by the growth of particles density in the ionosphere region from solar minimum to maximum.
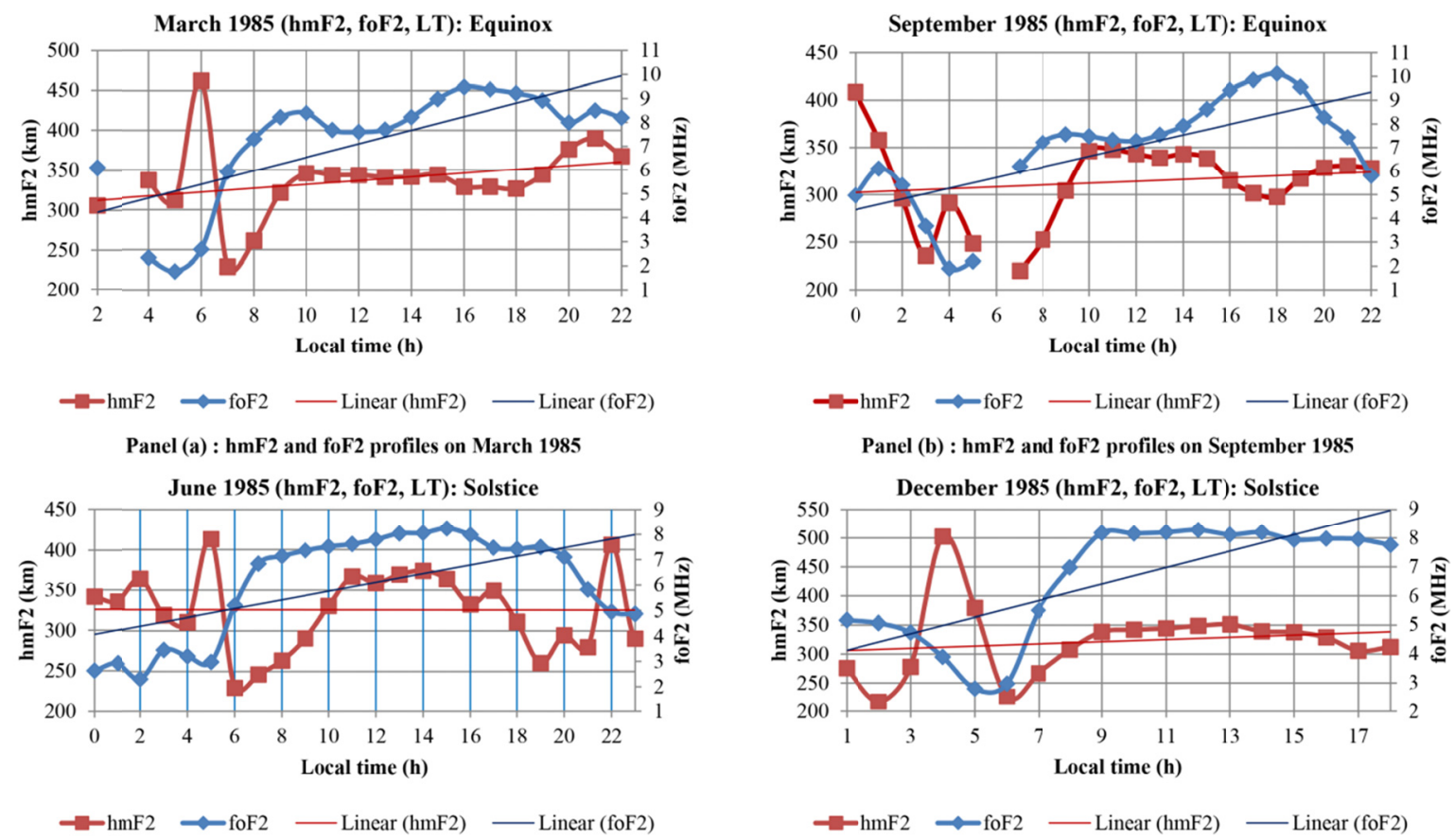

Panel (c) : hmF2 and foF2 profiles on June 1985

Panel (d) : hmF2 and foF2 profiles on December 1985

Figure 1. Time variation of $\mathrm{hmF} 2$ and foF2 on minimum solar cycle phase of $\mathrm{C} 22$ 

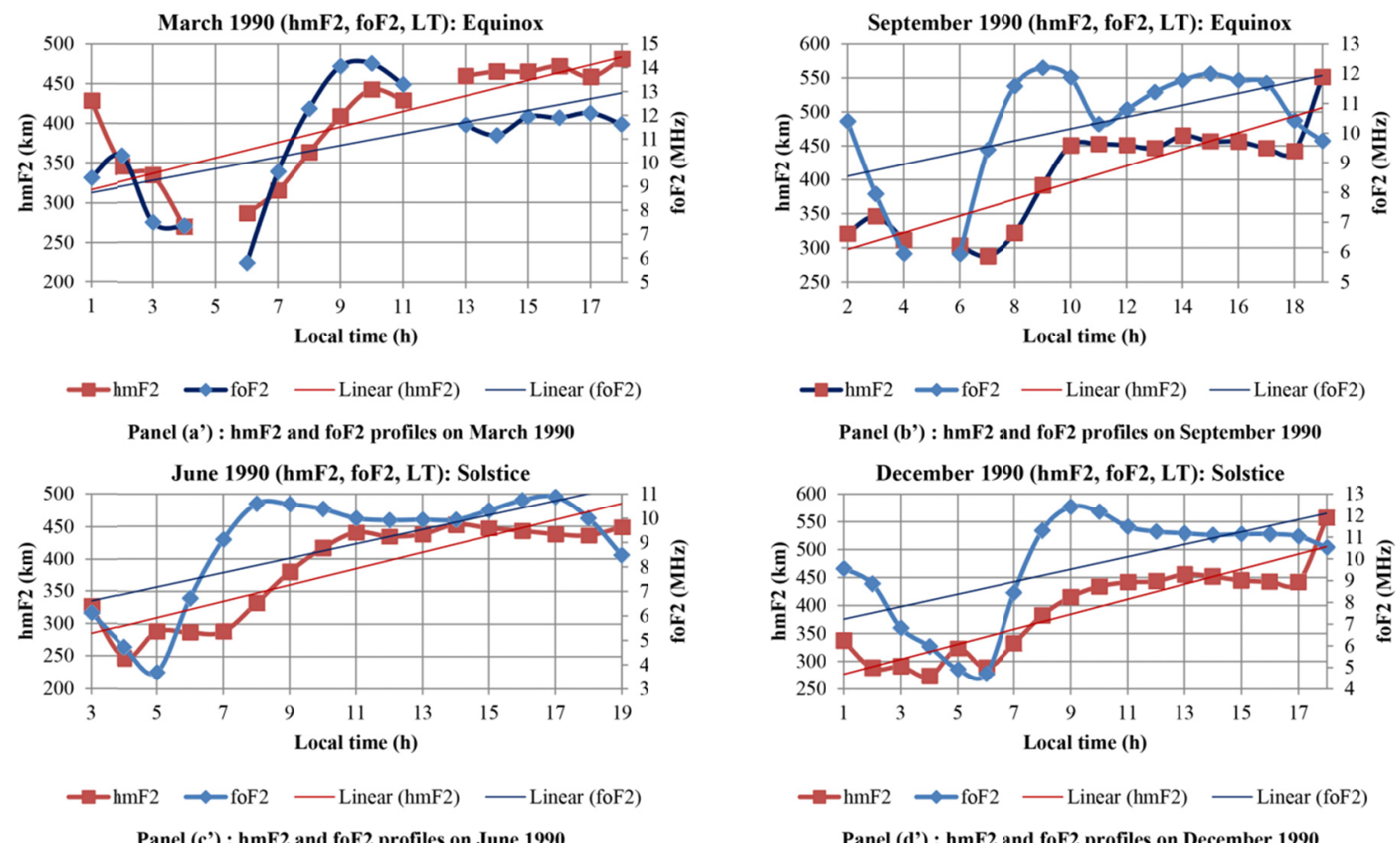

Figure 2. Time variation of $\mathrm{hmF} 2$ and foF 2 on maximum solar cycle phase of $\mathrm{C} 22$

\section{Conclusion}

During solar maximum, foF2 values are higher than those of foF2 on solar minimum. So, rather hmF2 is high, than foF2 is great. hmF2 influences the behavior of foF 2 by the growth of particles density in the ionosphere region from the minimum to the maximum of solar cycle phase. These results have good correlation with those found during the studies of foF 2 and $\mathrm{hmF} 2$ by Thermosphere Ionosphere Electrodynamics General Circulation Model (TIEGCM) and International Reference Ionosphere (IRI) models.

\section{Aknowledgment}

Authors thank Télécom Bretagne for providing data and especially Dr. Rolland Fleury for his assistance during their stay at IMT Atlantique (Brest, France) on 2017.

\section{References}

Dudeney, J. R. (1983) Journal of Atmospheric and Solar-Terrestrial Physics, 45, 629-640. https://doi.org/10. 1016/S0021-9169(83)80080-4

Gnabahou, A., \& Ouattara, F. (2012) Ionosphere Variability from 1957 to 1981 at Djibouti Station, European Journal of Scientific Research, 73(3), 382-390.

Ouattara F., Zoundi, C., \& Fleury, R. (2012) Comparison between CODG TEC and GPS based TEC observations at Koudougou station in Burkina Faso, Indian Journal of Radio \& Space Physics, 41, 617-623.

Ouattara, F. (2013) IRI-2007 foF2 Predictions at Ouagadougou Station during Quiet Time Periods from 1985 to 1995. Archives of Physics Research, 4, 12-18.

Ouattara, F., \& Nanéma, E. (2013) hmF2 quiet time variations at Ouagadougou and comparison with IRI-2012 and TIEGCM predictions during solar minimum and maximum, Archives of Applied Science Research, 5(5), 55-61.

Ouattara, F., Nanéma, E. (2014) Quiet time foF2 variation at Ouagadougou station and comparison with TIEGCM and IRI-2012 predictions for 1985 and 1990. Physical Science International Journal, 4(6), 892-902.

Zerbo, J. L., Ouattara, F., Zoundi, C., \& Gyébré, A. (2011) Solar cycle 23 and geomagnetic activity since 1868. Revue CAMES, série A., 12(2), 255-262. 
Zhang, S. R., Oliver, W. L., Holt, J. M., \& Fukao, S. (2003). Ionospheric data assimilation: Comparison of extracted parameters using full density profiles and key parameters. Journal of Geophysical Research: Space Physics, 108(A3), 1131. https://doi.org/10.1029/2002JA0009521

\section{Copyrights}

Copyright for this article is retained by the author(s), with first publication rights granted to the journal.

This is an open-access article distributed under the terms and conditions of the Creative Commons Attribution license (http://creativecommons.org/licenses/by/4.0/). 